Ventsel E.S., Shchukin A.V., Orel A.V., Saienko N.V.

Kharkiv National Automobile and Highway University,

Kharkiv, Ukraine

E-mail: alexhome88@gmail.com

UDC 621.878

DOI: $10.31891 / 2079-1372-2019-91-1-40-47$

\title{
INFLUENCE OF PHYSICAL AND MECHANICAL PARAMETRES ON THE STRUCTURAL ADAPTABILITY OF TRIBO COUPLINGS
}

In the process of tribo units friction and wear, structural adaptability of materials occurs. The structure and properties of the surface layers are formed, that ensure minimization of friction forces and a tribo unit wear rate. Thus, two phenomena occur at the same time: structural adaptability of surfaces and structural adaptability of oil, i.e., complex structural adaptability can be observed. Considering the tribo coupling as a dynamic dissipative system, in which the energy of the macro mechanical movement is degraded, entropy is created.

Based on the analysis of the equation for the production of entropy, the conclusion was made about degradation of the structure of the substance. This fact can be interpreted as information about the secondary structures in the process of tribo unit adaptation.

Key words: wear, tribo coupling, steady state, dielectric susceptibility, structural adaptability.

\section{Introduction}

In the course of tribo units friction and wear, structural adaptability of the materials involved in these processes occurs. Thus, in the process of work the geometric characteristics of the contact change. This is observed in the initial period of operation of the tribo unit during the run-in, when the frequency of the surface becomes optimal with time [1, 2, 3], which ensures minimal losses due to friction and wear (micro geometric adaptability of surfaces).

Simultaneously, the structure and the properties of the surface layers are being formed, that minimize the tribo coupling's friction forces and a wear rate. Based on the consideration of general laws of friction and wear, B. I. Kostetskyi [4-6] constructed a theory of structural-energetic adaptation (structural adaptability) of the friction surface during mechanical and thermal processes. According to this theory, there is a certain range of loads and speeds of movement for all materials and environmental conditions, at which the normal course of mechanical and chemical wear occurs. At the same time, the structure of the surface layers acquires the greatest strength and resistance to physical and chemical effects for these conditions. Such structures were called secondary by B. I. Kostetskyi.

When the cleanliness of the surfaces, the structure and properties of the surface layers become optimal, the run-in process finishes, after which the friction force and the wear rate stabilize. In this case, the tribo coupling is adaptive to the conditions of friction, i.e., it is as close to the steady state as possible.

Similar processes of structural adaptability are also characteristic for lubricating oils. It is known [1, 7 , 8] that oil is intensely oxidized in the initial period of its usage, which is followed by generation of polar-active components capable of creating a strong adsorbed boundary film on the friction surface that reduces wear. With an increase in temperature for any reason, the stability of the boundary films decreases [9], they are desorbed and that results in a wear increase. However, together with increasing the temperature, the generation of polar-active components, which form secondary boundary films under these conditions, also increases. As a result, the processes of friction and wear stabilize again. Under certain conditions, in the absence of boundary films, selfgenerated organic films may be formed, discovered by M. V. Raiko in gear drives [10].

At the same time, in the initial period of work, the content of mechanical impurities is rapidly increasing in the oil, which can reduce friction and wear due to the separating action. The essence of this phenomenon is that with the discrete contact of surfaces through particles, which reduce electrostatic wear [11], the sizes of mechanical impurities, as a rule, enhances the thickness of the boundary oil films. The abrasive action of the surfaces disperses these particles, bringing them in size to the thickness of the oil film. This helps to increase the adsorption activity of particles, the formation of a protective layer from oxidation products on them, which leads to an increase in the anti-wear properties of the oil. The formation of particles of the adsorbed film is the act that characterizes the adaptability of the oil to the conditions of friction.

Besides, mechanical particles provide self-regulation of the antifriction surface separation, which means that suspended particles contained in the oil are continuously destroyed and extracted. They partly go along with the oil to the combustion chambers of the engines or go away with leaks in the leakiness of hydraulic systems, being selected by filters. However, as soon as their amount becomes insufficient to provide a separating action, the surfaces begin to contact directly by micro ridges, which leads to the emerging of new particles. 
When the amount of polar-active and mechanical impurities for specific conditions of friction becomes sufficient to ensure minimal forces of friction and wear, the processes of oxidation and accumulation of impurities are stabilized.

The whole complex of products formed in the oil is a result of their "run-in", i.e. structural adaptability, which can also be considered as a phenomenon of formation of secondary structures in the oil.

Meanwhile, oils are less stable in their properties than surfaces. Therefore, after a certain period of time, the properties of oils deteriorate due to the action of additives, changes in viscosity, etc. Replacing waste oils with fresh ones requires again their adaptation to conditions of friction, i.e. the need for re-running the oil.

Thus, the following two phenomena occur simultaneously in the tribo coupling: structural adaptability of surfaces and structural adaptability of oil, i.e. complex structural adaptability can be observed [12]. While theoretical studying this phenomenon, we will consider the tribo coupling as a dynamic dissipative system in which degradation of energy of macro mechanical movement is realized, i.e. entropy is created. According to the model of L. Yu. Bershadskyi, the tribo system includes excitatory volumes of materials of the friction surface and the lubricating layer, in which positive entropy production is realized through any mechanisms.

\section{The purpose and problem statement}

The purpose of the work is to establish the influence of physical and mechanical parameters (thermal conductivity, force of friction and magnetic susceptibility) on the structural adaptability of tribo couplings to friction conditions and intensive wear.

\section{Presentation of research materials}

Since a general theory for various types of tribo couplings can hardly be constructed, the thermodynamic method of studying various types of friction is of particular interest. The principle of the minimal energy dissipation, formulated by L. Onsager, should obviously be considered the most common method of this kind, which was generalized by I. Prigozhin as the principle (theorem) of the minimum entropy production, according to which when a system approaches a steady state under given constant conditions at the boundary of the system, entropy decreases and takes the minimum value.

We define the entropy production as:

$$
\tilde{S}=\frac{d^{2} S}{d t \cdot d V}
$$

With linear relationships of a thermodynamic flux, which in this case can be understood as densities of fluxes $\vec{j}_{i}$, and thermodynamic forces $\vec{X}_{i}$, the volumetric density of entropy can be represented as:

$$
\tilde{S}=\sum \vec{j}_{i} \cdot \vec{X}_{i}
$$

To calculate production of the entropy in a tribo unit, first we write down the first law of thermodynamics for a unit of volume of a tribo unit located in an electric field $\vec{E}$, caused, for example, by a contact difference of potentials, and also in a magnetic field $\vec{H}$ :

$$
T d \tilde{S}=d \vec{U}-F d\left(\frac{1}{\Omega J}\right)-\mu d n-d \vec{P} \vec{E}-d \rho_{q} \varphi-\vec{H} d \vec{I}
$$

It is easy to show that the value $\frac{1}{\Omega J}$ is a displacement $d \vec{l}$ related to the physically infinitely small volume $\Delta V \rightarrow 0$ of the wear-prone substance, i.e. $d\left(\frac{1}{\Omega J}\right)=\frac{d l}{a V}$. The introduction of this value was the result of averaging over the volume of the energy characteristics of the whole tribo unit.

Therefore, equation (1) is a local basic equation of thermodynamics with respect to the wear-prone substance, which is located in the tribo unit (the zone of intense wear). Let us present the density of internal energy $\tilde{U}$ in the form:

$$
\tilde{U}=\tilde{U}_{n}+\vec{U}_{Q}+\tilde{U}_{E, H}+\tilde{U}_{\Phi}
$$

Where:

$$
\vec{U}_{Q}=c_{V} T ; c_{V}=\frac{1}{V}\left(\frac{\partial Q}{\partial T}\right)_{V} ; \tilde{U}_{E . H}=\frac{\varepsilon_{0} E^{2}}{2}+\frac{\mu_{0} H^{2}}{2}
$$


The value $\tilde{U}_{\Phi}$ can be expressed in terms of the integrated density of the electromagnetic radiation flux using the modified formula of N. Umov:

taking into account the law of Stefan-Boltzmann:

$$
R=\tilde{U}_{\Phi} \frac{c}{4}
$$

$$
\tilde{U}_{\Phi}=\frac{4}{c} \alpha \sigma T^{4}
$$

where $\alpha<1$ is the absorption coefficient.

Denoting $4 a / c=\beta$ we receive:

$$
\tilde{U}_{\phi}=\beta \sigma T^{4}
$$

Now let us try to receive expressions for the extensional derivative of entropy $\vec{S}$.

The linear relationship between the density of fluxes $\vec{j}_{i}$ and thermodynamic forces $\vec{X}_{i}$ is assumed in accordance with expression (1).

Due to the fact that the choice of fluxes and thermodynamic forces is not in principle unequivocal, we will agree on their choice, in accordance with the equations:

$$
\begin{gathered}
\vec{X}_{i}=\operatorname{grad}\left(\frac{\partial \tilde{S}}{\partial x_{i}}\right), \\
-\operatorname{divj}_{i}=\frac{\partial x_{i}}{\partial t} .
\end{gathered}
$$

We keep in mind that for a standard state, $\frac{\partial x_{i}}{\partial t}$ should be understood as the density of the source $q_{i}$ of the corresponding generalized force in accordance with the continuity equation:

$$
\frac{\partial x_{i}}{d t}=-\operatorname{div} \vec{j}_{i}+q_{0}
$$

We first determine the thermodynamic force $\vec{X}_{U}$ corresponding to the internal energy $\tilde{U}$, for which, on the basis of equation (5), we differentiate (1) by $U$ :

$$
\vec{X}_{U}=\operatorname{grad}\left(\frac{\partial \tilde{S}}{\partial U}\right)=\operatorname{grad}\left(\frac{1}{T}\right)=-\frac{1}{T^{2}} \operatorname{grad} T .
$$

The density of the internal energy flux corresponds to this thermodynamic force:

$$
\vec{j}_{U}=\vec{j}_{\Pi}+\vec{j}_{Q}+\vec{j}_{E, H}+\vec{j}_{\Phi} \text {. }
$$

Assuming that in the steady state there are no sources of internal potential energy, i.e., $j_{\Pi}=0$, we have:

$$
\vec{j}_{U}=\vec{j}_{Q}+\vec{j}_{E, H}+\vec{j}_{\Phi}
$$

The expressions for the density of heat fluxes $\vec{j}_{Q}$, electromagnetic field $\vec{j}_{E, H}$ and thermal electromagnetic radiation $\vec{j}_{\Phi}$ are known from the laws of Fourier, Poiting (more precisely, the expressions for the Poiting vector) and Stefan-Boltzmann respectively

$$
\begin{aligned}
& \vec{j}_{Q}=-\gamma \operatorname{grad} T, \\
& \vec{j}_{E, H}=[\vec{E}, \vec{H}], \\
& \vec{j}_{\Phi}=\alpha \sigma T^{4} \vec{\tau}_{0} .
\end{aligned}
$$

Let us show on the example of the Poiting vector that its expression (9b) is a consequence of (6). 
In fact, in accordance with (6)

$$
-\operatorname{divj_{E,H}}=\frac{d \tilde{U}_{E, H}}{d t} .
$$

However, since in the steady state $\frac{d x_{i}}{d t}=0$, then, as follows from equation (7):

$$
\operatorname{divj_{i}}=q_{i} .
$$

As the density $q_{i}$ of the source of the electromagnetic field, the following value should be understood:

$$
q_{E, H}=\frac{\partial}{\partial t}\left(\frac{\varepsilon_{0} E^{2}}{2}+\frac{\mu_{0} H^{2}}{2}\right)
$$

Then in accordance with expression (10):

$$
d i v \vec{j}_{E, H}=\frac{\partial}{\partial t}\left(\frac{\varepsilon_{0} E^{2}}{2}+\frac{\mu_{0} H^{2}}{2}\right)=\varepsilon_{0} \vec{E} \frac{\partial \vec{E}}{\partial t}+\mu_{0} \vec{H} \frac{\partial \vec{H}}{\partial t}=E \frac{\partial \vec{D}}{\partial t}+H \frac{\partial \vec{B}}{\partial t} .
$$

We will find derivatives $\frac{\partial \vec{D}}{\partial t}$ and $\frac{\partial \vec{B}}{\partial t}$ from the Maxwell's equation, neglecting the conduction current compared with the bias current due to the low electrical conductivity of the oil film:

$$
\operatorname{rot} \vec{H}=\frac{d \vec{D}}{d t} ; \operatorname{rot} \vec{E}=-\frac{d \vec{B}}{d t} .
$$

Then:

$$
\operatorname{div} \vec{j}_{E, H}=\vec{E} \operatorname{rot} \vec{H}-\vec{H} \operatorname{rot} \vec{E} .
$$

We rewrite the last-mentioned equation using the operator $\vec{\nabla}$ :

$$
\vec{\nabla} \vec{j}_{E, H}=\vec{E}[\vec{\nabla}, \vec{H},]-\vec{H}[\vec{\nabla}, \vec{E}] .
$$

Performing a cyclic permutation in the mixed products of vectors, we receive:

$$
\vec{\nabla} \vec{j}_{E, H}=\vec{\nabla}[\vec{H}, \vec{E}]-\vec{\nabla}[\vec{E}, \vec{H}] .
$$

Exchanging the positions of $\vec{E}$ and $\vec{H}$ in the first component of the right part, we have:

Whence it follows that:

$$
\vec{\nabla} \vec{j}_{E, H}=-\vec{\nabla}[\vec{E}, \vec{H}]-\vec{\nabla}[\vec{E}, \vec{H}]=-2 \vec{\nabla}[\vec{E}, \vec{H}] \text {, }
$$

$$
\vec{j}_{E, H}=-2[\vec{E}, \vec{H}] \text {. }
$$

The Poiting vector coefficient 2 arose due to the fact that each of the variables of macroscopic fields $\vec{E}, \vec{H}$ creates an electromagnetic wave. If only one of these fields is present, the coefficient 2 is absent. The minus sign in the resulting expression provides nonnegativeness of the scalar products of negative thermodynamic (8) by the value of also negative flux density, which ensures non-negative value of entropy production. For the same reason, the vector of density of the radiation flux should also be a negative value, which in principle could be shown as strictly as that for the Poiting vector, stipulated by the variable macroscopic fields.

With this circumstance in mind, equation (9) can be rewritten as follows:

$$
\begin{gathered}
\vec{j}_{Q}=-\gamma \operatorname{grad} T, \\
\vec{j}_{E, H}=-2[\vec{E}, \vec{H}], \\
\vec{j}_{\Phi}=\alpha \sigma T^{4} \vec{\tau}_{0} .
\end{gathered}
$$

Let us get onto the definition of thermodynamic forces and fluxes of other thermodynamic values.

First, we define the expression for the thermodynamic force $\vec{X}_{N}$ causing the flow of particles $\vec{j}_{N}=\frac{d^{2} N}{d \Omega d t} \vec{\tau}_{0}$

Assuming the value of the generalized coordinate $\vec{X}_{N}=n$ in equation (5) and taking into account (1), we receive: 


$$
\vec{X}_{N}=-\operatorname{grad}\left(\frac{\mu}{T}\right)
$$

neglecting effects similar to thermal diffusion it can be written:

$$
\vec{X}_{N}=\frac{-(\operatorname{grad} \mu)}{T} .
$$

The effective chemical potential is defined as:

$$
\mu=-F[\partial(1 / \Omega I) / d n]_{\tilde{S}, \tilde{U}, P \ldots} .
$$

It is easy to show that for a zone of uniform wear this value is equal to $\mu=-\frac{F}{n j \Omega}$.

Given that only the concentration $n$ of particles of wear and other impurities can be a function of the coordinates, we find the final thermodynamic force responsible for the flow of particles:

$$
\vec{X}_{N}=-\frac{|\vec{F}|}{T^{2} I \Omega} \operatorname{grad} n
$$

It is also easy to show that the density of the of particles flux $\vec{j}_{N}$ is related to their concentration $n$, the value of wear $J$ and the rate $v$ of displacement of the tribo coupling surfaces by the relation:

$$
\vec{j}_{N}=n I v \vec{\tau}_{0}
$$

In the presence of charged particles in an electric field $E$, electric current arises in the gap of the tribo coupling, whose density is determined in accordance with Ohm's law in a differential form by the expression:

$$
\vec{j}_{q}=\sigma_{0} \vec{E} \text {. }
$$

Since $\vec{E}=-\operatorname{grad} \varphi$, then:

$$
\vec{j}_{q}=-\sigma_{0} \operatorname{grad} \varphi .
$$

The thermodynamic force generating this current in accordance with equation (5) and taking into account (1), has the form:

$$
\vec{X}_{q}=\operatorname{grad}\left(\frac{\partial \tilde{s}}{\partial \rho_{q}}\right)=-\frac{\operatorname{grad} \varphi}{T} .
$$

In the presence of an electric field gradient, in the gap of the tribo coupling there occurs a flow of molecular dipoles with the density of:

$$
\vec{j}_{\Pi}=-\frac{d^{2}\left|\sum \vec{p}_{i}\right|}{d \Omega d t} \vec{\tau}_{0}
$$

The minus sign reflects the fact that when a dipole moves in a non-uniform field, its dipole moment, directed from a negative charge to a positive one, is antiparallel $\operatorname{grad}|\vec{E}|$.

The magnitude of the dipole current can be easily expressed through polarization $\vec{P}$, for which the numerator and denominator of relation (16) are multiplied and divided by the value $d h$ of the displacement of the dipole in the electric field during the time $d t$.

$$
\vec{j}_{\Pi}=-\frac{d^{2}\left|\sum p_{i}\right| d h}{d \Omega d t d h} \vec{\tau}_{0}=-\frac{d^{2}\left|\sum \vec{p}_{i}\right|}{d \Omega d h} \frac{d h}{d t} \vec{\tau}_{0}=-\frac{d\left|\sum \vec{p}_{i}\right|}{d V} U_{p} \vec{\tau}_{d}=-P U_{p} \vec{\tau}_{0} .
$$

where $U_{p}=\frac{d h}{d t}$ is the speed of movement of the dipoles in the electric field.

Since in the steady state the speed of the dipoles $U_{p}$ does not change, we can enter the mobility of the dipoles in the same way as it is done for free charges.

Let us assume that a dipole, moving under by a force $F=(\vec{p}$ grad $) \vec{E}=(\vec{p} \vec{\nabla}) \vec{E}$, is acted upon by a resistance force $\vec{F}_{c}$ proportional to its speed $\vec{U}_{p}$, i.e.:

$$
\vec{F}_{c}=-r \vec{U}_{p}
$$


Assuming that the dipole moves along the field gradient at a constant speed $\vec{U}_{p}$, we can write:

$$
(\vec{p} \operatorname{grad}) \vec{E}-r \vec{U} p=0
$$

then the speed of dipoles is:

$$
\vec{U}_{p}=\frac{p}{r} \operatorname{grad}|\vec{E}|
$$

The coefficient $\frac{p}{r}=b_{p}$ will be called the mobility of dipoles by analogy with the mobility of charges moving in an electric field.

We now note that the polarization $\vec{P}$ of the dielectric is related to the field density $\vec{E}$ inside the dielectric by the formula:

$$
\vec{P}=\varkappa \vec{E} \text {. }
$$

Assuming that the dipoles move in such a way that $\vec{p}$ is antiparallel to $\operatorname{grad}|\vec{E}|$, expression (17) can be written as:

$$
\vec{j}_{p}=\left(\vec{P} \vec{U}_{p}\right) \vec{\tau}_{0}=-|\vec{P}|\left|\vec{U}_{p}\right| \vec{\tau}_{0} .
$$

Substituting relations (18) and (19) into (20), we find the final expression for the flow of dipoles:

$$
\vec{j}_{p}=-\varkappa b_{p}|\vec{E}| \operatorname{grad}|\vec{E}| \text {. }
$$

Now we define the thermodynamic force $\vec{X}_{p}$ that creates this flow:

$$
\vec{X}_{p}=\operatorname{grad}\left(\frac{\partial \tilde{S}}{\partial P}\right)=-\frac{1}{T} \operatorname{grad}|\vec{E}| \text {. }
$$

In a similar way, we determine the flux density of magnetic dipoles $\vec{j}_{m}$ and the thermodynamic force $\vec{X}_{m}$ that creates this flux. Formally, this procedure is reduced to substituting the dielectric susceptibility $\varkappa$ by magnetic susceptibility $\varkappa_{m}$, the mobility of the electric dipoles $b_{p}$ by the mobility of the magnetic dipole moments $h_{m}$, the electric field density $\vec{E}$ by the magnetic field strength $\vec{H}$ and $\operatorname{grad}|\vec{E}|$ by $\operatorname{grad}|\vec{B}|$. In equations (21) and (22).

In the latter case, the symmetry is broken, since the strength characteristic of the magnetic field is its induction $\vec{B}$, and not strength $\vec{H}$.

Then the expression for the density of magnetic dipole flux $\vec{j}_{m}$ and the corresponding thermodynamic force $\vec{X}_{m}$ will have the form:

$$
\vec{j}_{m}=-\varkappa_{m} b_{m}|\vec{H}| \operatorname{grad}|\vec{B}| \text {. }
$$

It should be borne in mind that the flux density vector of magnetic dipoles can be directed both parallel to the field gradient and antiparallel to it, since $\varkappa_{m}$ can be both greater and less than 0 (the latter case occurs for diamagnetics).

Considering that $B=\mu_{0}\left(1+\varkappa_{m}\right) H$, expression (23) can be represented as:

$$
\vec{j}_{m}=-\varkappa_{m}\left(1+\varkappa_{m}\right) b_{m}|\vec{H}| \operatorname{grad}|\vec{H}|,
$$

a thermodynamic force corresponding to flow $\vec{j}_{m}$ :

$$
\vec{X}_{m}=-\frac{1}{T} \operatorname{grad}|\vec{H}| .
$$

Now you can write expressions for the volume density of entropy production, substituting expression (8), (11a, b, c), (12 - 15), (21 - 24) into equation (1): 


$$
\begin{gathered}
\tilde{S}=\frac{\operatorname{grad} T}{T^{2}}\left(\gamma \operatorname{grad} T+2[\vec{E}, \vec{H}]+\alpha \sigma T^{4} \tau_{0}\right)-\frac{\vec{f} V}{T n \omega} \operatorname{grad} n+ \\
+\frac{\sigma_{0}}{T}(\operatorname{grad} \varphi)^{2}+\frac{\varkappa}{T} b_{p}|\vec{E}|(\operatorname{grad}|\vec{E}|)+\left|\frac{\varkappa_{m}}{T}\left(1+\varkappa_{m}\right) b_{m}\right| \vec{H}\left|(\operatorname{grad}|\vec{H}|)^{2}\right| .
\end{gathered}
$$

\section{Conclusion}

The obtained expression for the volumetric density of entropy production allows to conclude that when approaching a steady state, the structures are found in a tribo coupling which are characterized by reduced thermal conductivity, friction forces and magnetic susceptibility.

Indeed, thermal conductivity is decreased due to depreciation of friction surfaces, and a decrease in electrical conductivity and viscosity (in the case of viscous friction): a decrease in dielectric and magnetic susceptibility prove the formation of structures with smaller dipole moments, and consequently, "simplification" of the structure of the substance in a tribo coupling, which was shown in the works of B. I. Kostetskyi and, as noted above, was called structural adaptability.

\section{Designations}

$S$ - entropy; $t$ - time;

$V$ - volume;

$j_{i}-$ flux density;

$\vec{x}_{i}$ - thermodynamic force;

$T$ - temperature;

$\tilde{S}$ - volumetric density of entropy;

$\vec{U}$ - volumetric density of internal energy;

$F$ - friction force;

$\Omega-$ tribo unit surface area;

$I$ - wear rate (wear);

$\mu$-effective chemical potential;

$n$ - concentration of impurity particles in the tribo unit volume;

$\vec{p}-$ polarization vector;

$\vec{E}$ - electric field strength;

$\vec{p}_{q}-$ electric charge density;

$\varphi$ - electric potential of the tribo unit point;

$\vec{H}$ - magnetic field strength;

$\vec{I}$ - magnetization;

$l$ - moving;

$U_{p}$ - density of the internal potential energy of interaction of micro particles, which have no sources in the steady state;

$\vec{U}_{Q}$ - thermal energy density;

$\tilde{U}_{E, H}$ - density of the macroscopic field energy;

$\tilde{U}_{\Phi}-$ density of photon gas energy (electromagnetic thermal radiation);

$c_{V}$ - heat capacity at constant volume;

$\varepsilon_{0}-$ electric constant;

$\alpha-$ coefficient of thermal radiation absorption;

$\sigma-$ Stefan-Boltzmann constant;

$\vec{P}$ - polarization;

$\vec{D}$ - vector of electric field induction; 
$\vec{B}$ - vector of electromagnetic field induction;

$\vec{\tau}_{0}-$ a single vector coinciding in direction with gradn;

$\sigma_{0}-$ specific conductivity of the contact zone;

$\vec{p}$ - dipole moment;

$F_{c}-$ resistance force;

$\vec{U}_{p}$ - dipole rate;

$r-$ coefficient of resistance;

$\gamma$ - thermal conductivity;

$\varkappa-$ dielectric susceptibility;

$j_{m}-$ flux density of magnetic dipoles;

$\varkappa_{m}$ - magnetic susceptibility;

$\eta$ - coefficient of viscosity.

\section{References}

1. Vencel Ye.S. Pidvishchennya yakosti mastil, paliv i tribovuzliv mashin : monografiya / Ye.S. Vencel, O.V. Orel, O.V. Shchukin. - H.: FOP Brovin O.V., 2017. - 264 s.

2. Vencel Ye.S. Uluchshenie kachestva i povyshenie srokov sluzhby neftyanyh masel / Ye.S. Vencel, S.G. ZHalkin, N.I. Dan'ko. - Har'kov : UkrGAZHT, 2003. - 168 s.

3. Ye. Ventsel, O. Orel, O. Shchukin, N. Saienko, A. Kravets', Dependence of Wear Intensity on Parameters of Tribo Units, Tribology in Industry, Vol. 40, No. 2, pp. 195-202, 2018, DOI: 10.24874/ti.2018.40.02.03

4. Kosteckij B. I. Nadezhnost' i dolgovechnost' mashin Nosovskij / B. I. Kosteckij, I. G Nosovskij, L.I. Bershadskij, A. K. Karaulov. - Kiev: Tekhnika, 1975. - 405 s.

5. Kosteckij B.I. Trenie, smazka i iznos v mashinah / B.I. Kosteckij. - K.: Tekhnika, 1970. - 396 s.

6. Kosteckij B.I. O roli vtorichnyh struktur v formirovanii mekhanizmov treniya, smazochnogo dejstviya i iznashivaniya // Trenie i iznos. - 1980. - T. 1, № 4. - S. $622-637$.

7. Vencel S. V. Primenenie smazochnyh masel v dvigatelyah vnutrennego sgoraniya / S.V. Vencel. M.: Himiya, 1979. $-240 \mathrm{~s}$.

9. Matveevskij R. M. Temperaturnaya stojkost' granichnyh smazochnyh sostavov tverdyh smazochnyh pokrytij pri trenii metalov i splavov / R. M. Matveevskij. - M.: Nauka, 1971. - $226 \mathrm{~s}$.

10. Rajko M. V. Smazka zubchatyh peredach / M. V. Rajko. - Kiev: Tekhnika, 1970. - 194 s.

11. Myshkin N.K. Trenie, smazka, iznos. Fizicheskie osnovy i tekhnicheskie prilozheniya tribologii / N.K. Myshkin, M.I. Petrokovec. - M.: FIZMATLIT, 2007. - 368 s.

12. Povyshenie resursa tribosopryazhenij aktivirovannymi metodami inzhenerii poverhnosti / P.A. Vityaz' i [dr.]. - Minsk: Belarus. Navuka, 2012. - 452 s.

Венцель Є.С., Щукін О.В., Орел О.В., Саєнко Н.В. Вплив фізико-механічних показників на структурну пристосованість трибосполучень.

У процесі тертя і зношування трибовузлів відбувається структурна пристосованість матеріалів. Формується структура і властивості поверхневих шарів, що забезпечують мінімізацію сил тертя і швидкості зношування трибосполучень. Так, одночасно протікають два явища: структурна пристосованість поверхонь і структурна пристосованість мастила, тобто має місце комплексна структурна пристосованість. Розглядаючи трибосполучення як динамічну дисипативну систему, в якій реалізується деградація енергії макромеханічного руху, створюється ентропія.

На підставі аналізу рівняння для виробництва ентропії був зроблений висновок про деградацію структури речовини. Цей факт можна інтерпретувати як інформацію про вторинних структурах в процесі адаптації трибосполучень.

Ключові слова: зношування, трибосполучення, стаціонарний стан, діелектрична сприйнятливість, структурна пристосованість. 